\title{
NON-EQUILIBRIUM THERMODYNAMICS AND OUTBURST HAZARD OF A COAL BED
}

\author{
A.D. ALEXEEV, E.P. FELDMAN
}

PACS 62.20.Dc, 76.60.-k (C) 2012
Institute for Physics of Mining Processes, Nat. Acad. of Sci. of Ukraine

(Donetsk 83114, Ukraine; e-mail: feldman@ depm.fti.ac. donetsk.ua)
We present the theoretical description of the non-equilibrium thermodynamics of a gas-bearing coal bed and the estimation of the outburst hazard of coal beds.

The conception of a coal bed as a fractured porous medium containing liquid and gaseous fluids was substantiated and developed by a number of authors (see [1-4]). The estimations of the elastic energy of a coal bed, the energy of the inner surface, and the energy of a compressed gas in cavities of a bed were obtained. Basing on the energy approach, the attempts were made to predict the gas dynamic phenomena in mines, i.e., the unexpected outbursts of coal, rock, and gas [5].

Using the modern concepts of non-equilibrium thermodynamics, the present work contains a necessarily simplified construction of the kinetic theory of main irreversible processes of fracture and gas flow preceding the unexpected coal and gas outbursts from a coal bed.

The system to be considered includes the solid frame with cavities (pores, cracks, channels, and lacunas) filled with gas (it is mainly methane in practice). The description can be applied both to a coal bed and surrounding rocks. The present work deals with coal.

The rocks containing a coal bed play the role of a thermostat controlling the external (rock) pressure $P_{m}$ and the temperature $T$. The role of parameters determining a deviation of the system from the state of thermodynamic equilibrium is played by the gas pressure $P$ (or, at option, by its density $\rho_{g}$, related to the pressure by the ideal gas equation $P=\rho_{g} T, T$ is expressed in energy units) and the bed voidage $\gamma$, i.e. the ratio of the total volume of cavities to the bed volume.

As the pressure and the temperature are prescribed from the outside, the description of both equilibrium state and kinetics of a coal bed requires the definition of Gibbs' potential of the bed. Here, we write down separate terms of this potential per unit volume.
1. One part of the potential is the elastic energy of the coal bed expressed in terms of stresses (in our case, in terms of the pressure). It was found earlier [6] as

$$
\varphi_{e}=\frac{1}{2(1-\gamma)}\left[\frac{\left(P_{m}-\gamma P\right)^{2}}{K}+\frac{3 \gamma}{4 G}\left(P_{m}-P\right)^{2}\right] .
$$

Here, $K$ is the compression modulus, and $G$ is the shear modulus.

2. The energy of the inner surface of a massif is proportional to the surface area

$\varphi_{s}=\gamma \frac{\sigma}{\Lambda}$

where $\sigma$ is the energy of unit area of the coal surface, and the size $\Lambda$ is equal to the volume of the crack-pore space divided by the surface of this "cave". For instance, if the voidage is formed by spherical pores of the same radius $R$, the parameter $\Lambda=R / 3$; if we deal with identical cracks, $\Lambda$ coincides with the crack gaping.

3. Gibbs' potential of unit volume of the ideal gas is equal to $P \ln \frac{P}{P_{T}}$, where $P_{T}$ is the known function of the temperature depending on the gas type [7]. We suggest here that gas is located only in voids,

$\varphi_{g}=\gamma P \ln \frac{P}{P_{T}}$

After the summation of these three contributions to Gibbs' potential, we obtain

$$
\begin{aligned}
& \varphi(P, \gamma)=\gamma \frac{\sigma}{\Lambda}+\gamma P \ln \frac{P}{P_{T}}+\frac{1}{2(1-\gamma)} \times \\
& \times\left[\frac{\left(P_{m}-\gamma P\right)^{2}}{K}+\frac{3 \gamma}{4 G}\left(P_{m}-P\right)^{2}\right] .
\end{aligned}
$$

Without the mining extraction and natural geomechanical impacts, the bed is in equilibrium, and the distribution of pressure and voidage does not change in time. In that case, the pressure distribution with respect to the course of a bed was investigated in $[6,8]$ in detail. 
We can now trace the evolution of $\gamma$ and $P$ in time, if the equilibrium of a massif is disturbed by the mining extraction.

We start from the voidage. As far as it is a nonconserved parameter, its kinetics can be adequately described with an equation of Landau-Khalatnikov's type

$\frac{d \gamma}{d t}=-\Gamma \frac{\partial \varphi(P, \gamma)}{\partial \gamma}$

where $\Gamma$ is the kinetic coefficient inverse to the voidage evolution time (actually, it is the time of evolution of gas-filled cracks, see [9]).

If the derivative $\partial \varphi(P, \gamma) / \partial \gamma$ is positive, the voidage should be reduced, according to (5). In fact, the reduction is not observed, cracks and pores do not heal, staying in the initial state. If $\partial \varphi(P, \gamma) / \partial \gamma$ is negative, the voidage increases. We believe that this case corresponds to a possibility of the massif destruction. In other words, the massif is hazardous with respect to the outburst. So, a prerequisite of the massif outburst hazard is the validity of the inequality

$$
\frac{\sigma}{\Lambda}+P \ln \frac{P}{P_{T}}+\frac{P_{m}}{2 K}\left(P_{m}-2 P\right)+\frac{3}{8 G}\left(P_{m}-P\right)^{2}<0 .
$$

The first "surface" term on the left-hand side of (6) is always positive, the second "gas" term is always negative (the value of $P_{T}$ is higher than $P$ by several orders); the sum of the "elastic" terms can be of any sign. In the majority of practical cases, the first term in (6) is much greater of the rest of them. That is why the outburst is a rare phenomenon.

However, there are some cases, when the gas component compensates the surface one. In other words, the gas pressure is high enough to cause the breakdown, and the elastic terms start playing the important role. It is clear that we must give representative estimations.

The specific surface energy depends on the coal rank and is about $\sigma \approx 10 \mathrm{~J} / \mathrm{m}^{2}[2]$. The fractal scale is $\Lambda \approx$ $5 \times 10^{-8} \mathrm{~m}$, i.e. $\sigma / \Lambda \approx 2 \times 10^{8} \mathrm{~J} / \mathrm{m}^{3}=200 \mathrm{MPa}$. We evaluate the gas part, by suggesting that $P \approx 100 \mathrm{~atm}=$ $10 \mathrm{MPa}$ at a depth of about $1 \mathrm{~km}$. The calculation of $P_{T}$ according to the known formula in [7] for methane yields $P_{T} \cong 10^{10} \frac{\mathrm{J}}{\mathrm{m}^{3}}=10^{4} \mathrm{MPa}$. Consequently, $P \ln \left(P / P_{T}\right) \cong$ $-7 \times 10^{7} \frac{\mathrm{J}}{\mathrm{m}^{3}}$. The terms related to the stressed volume state are estimated, by using the following data: $P_{m}=$ $25 \mathrm{MPa}$ at a depth of $1 \mathrm{~km}, G \approx 800 \mathrm{MPa}[1], 3 P_{m}^{2} / 8 G \approx$ $0.3 \times 10^{6} \mathrm{~J} / \mathrm{m}^{3}$. These terms are by $1-2$ orders less than two first terms.

Inequality (6) is not valid for the abovementioned (usual) characteristics, and the situation is not hazardous. The outburst has a noticeable probability only if

$\frac{\sigma}{\Lambda}-P \ln \frac{P_{T}}{P} \approx 0$.

A high gas pressure (several tens of atmospheres), a low surface energy of coal (below $10 \mathrm{~J} / \mathrm{m}^{2}$ ), and the presence of voids of big sizes in coal (the gaping of cracks is more than $1 \mu \mathrm{m}$ ) are required. In addition, at the maximum abutment pressure on the bed of "weakened" coal (when $G$ can be reduced down to $200 \mathrm{MPa}$ ), the elastic components can be a noticeable (about 10\%) part of the gas component.

Figure presents a diagram in the $\left(P, P_{m}\right)$ coordinates, which illustrates the hazardous and safe areas with respect to the outburst.

While calculating the curve separating the mentioned areas, we took into account that, as $P$ changes within the limits of an order of magnitude, the logarithm value in (6) may be thought of as a constant. For the sake of definiteness, we suppose $\ln \frac{P}{P_{T}}=-7$.

It is seen in Figure among other things that the outburst is impossible at the gas pressure below $P_{\mathrm{cr}} \approx \frac{\sigma}{7 \Lambda}$. The critical point denotes the equality of the rock pressure and the gas pressure at a level from one hundred up to one thousand of atmospheres. This means that the outbursts are mostly expected at large depths and in the beds with high methane capacity $[10,11]$.

Unlike the voidage, the pressure is a conserved parameter. When determining the form of the equation for $P$, one should take the conservation law of the gas amount into account. Generally, the derivation of this equation follows the derivation of Darcy's equation for the gas filtration. The principal distinction is in the fact that the driving force of the filtration is the chemical potential gradient which can not be reduced to the pressure gradient in our case because of the additional elastic terms in (4). We write down this equation in the actual one-dimensional case as

$$
\begin{aligned}
& \gamma \frac{\partial P(x, t)}{\partial t}= \\
& =D_{f}\left[\frac{\partial^{2} P(x, t)}{\partial x^{2}}-\left(\frac{1}{K}+\frac{3}{4 G}\right) \frac{\partial}{\partial x}\left(P \frac{\partial P_{m}(x)}{\partial x}\right)\right]
\end{aligned}
$$

where $D_{f}$ is the filtration coefficient determined by the geometry of filtration volume, voidage, and gas viscosity, and $P_{m}(x)$ is the inhomogeneous abutment pressure.

Contrary to standard Darcy's equation, Eq. (8) includes a term indicating the influence of the external field $P_{m}(x)$ on the rate and the direction of a gas flow. 


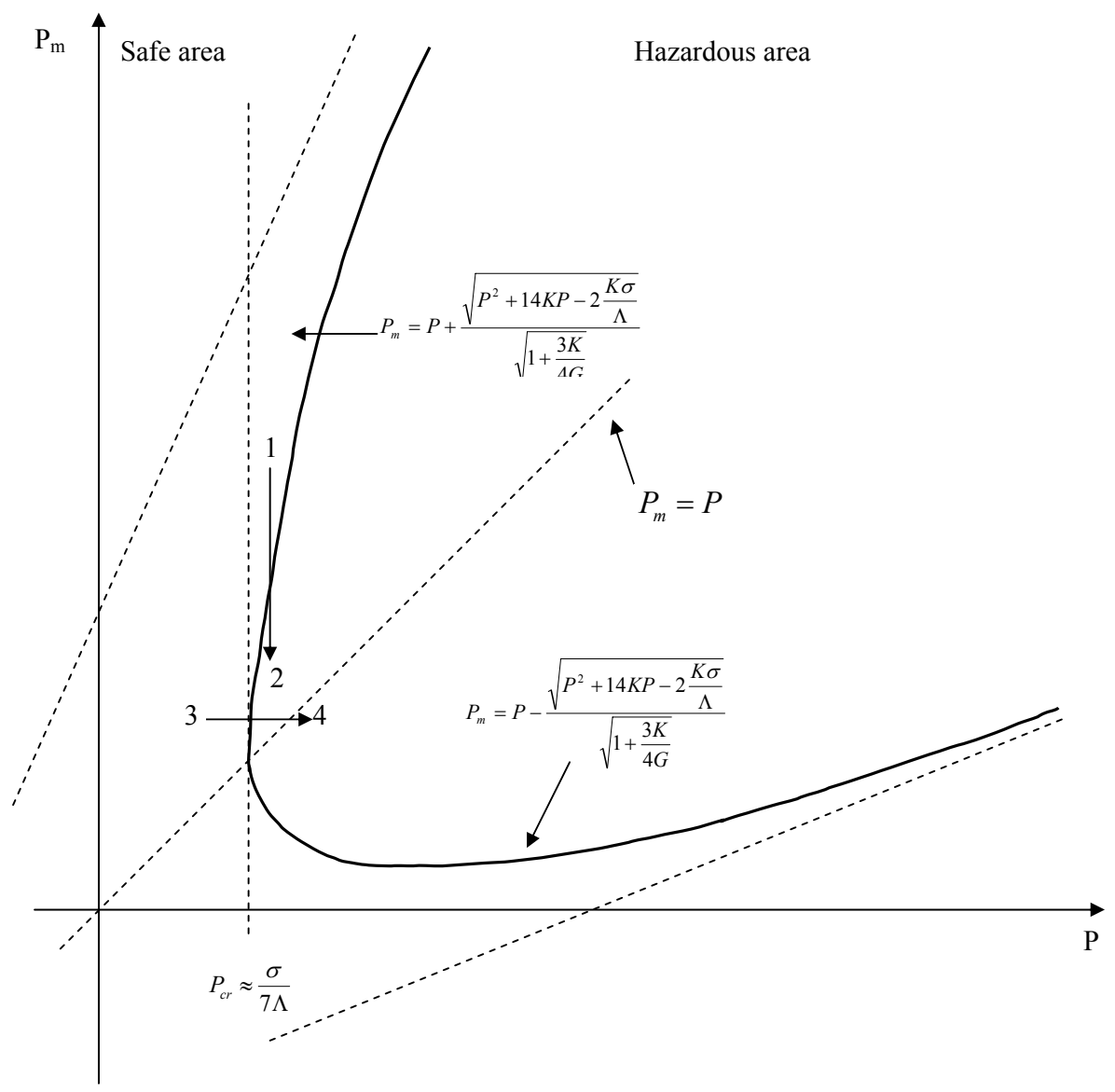

In particular, it is seen that the growth rather than the reduction of the gas pressure takes place near the maximum abutment pressure, where $\frac{d^{2} P_{m}}{d x^{2}}<0$, within a time interval, when the gas pressure may be considered as a homogeneous one.

There are two main possibilities for a bed to transit in a non-equilibrium hazardous state. First, it is the stress fault (bed relieving, see line $1 \rightarrow 2$ in Figure). The second possibility for the bed activation is an increase (at least, temporary and local) in the gas pressure (line $3 \rightarrow 4$ in Figure). As a matter of fact, the gas pressure is reduced in the course of extraction because gas leaves the coal bed for a mined-out space. Nevertheless, the paradoxical effect results in the situation where the gas pressure increases during a definite time interval in the area of the maximum abutment pressure (inhomogeneous abutment pressure on the bed arises due to a redistribution of the rock pressure after the extraction work).

The increase of the gas pressure because of the difficulty of filtration comes to tens per cent of its initial content in a coal bed. This amount can be sufficient for the outburst activation.

Thus, the results are as follows:

1. Non-equilibrium thermodynamics of a gas-coal massif (bed) has been built, basing on the account for main components of its thermodynamic potential. The parameters of the macroscopic state are the gas pressure and the voidage of the massif, and the bearing strata are considered as a thermostat controlling the external pressure and the temperature of the bed.

2 . The use of the modern concepts of conserved and non-conserved order parameters allowed us to make a correct derivation of the kinetic equations for the gas pressure and the voidage of a massif, respectively.

3. The diagram of the gas pressure vs the rock pressure is presented with the distinguished area, where the gas dynamic phenomenon of coal and gas outburst becomes possible. The realistic evaluations of critical outburst parameters are given.

4. A prediction is made that the gas pressure in strata can grow during a definite time interval in the area of 
the maximum abutment pressure that can activate the gas and coal outburst.

1. B.M. Ivanov, G.N. Feit, and M.F. Yanovskaya, Mechanical and Physico-Technical Properties of Coals from Outburst-Hazard Beds (Nauka, Moscow, 1979) (in Russian).

2. A.D. Alexeev, Physics of Coal and Mining Processes (Naukova Dumka, Kiev, 2010), (in Russian).

3. K.R. McCall and R.A. Gayer, Phys. Rev. B 43, 1411 (1991).

4. A.D. Alexeev, E.P. Feldman, T.N. Melnik, T.A. Vasilenko, and G.P. Starikov, Ukr. J. Phys. 49, 86 (2004).

5. G.P. Starikov, Fiz.-Tekh. Probl. Gorn. Proizv. 7, 214 (2004).

6. A.D. Alexeev and E.P. Feldman, Techn. Phys. Lett. 34, 609 (2008).

7. L.D. Landau and E.M. Lifshitz, Statistical Physics (Pergamon Press, New York, 1980).

8. A.D. Alexeev, E.P. Feldman, and N.A. Kalugina, J. of Techn. Phys. 80, 57 (2010).
9. O.V Volodarskaya, V. O. Streltsov, E.P. Feldman, and V.M. Yurchenko, Fiz. Tv. Tela 34, 618 (1992).

10. S.A. Khristianovich and R.L. Salganik, Sudden Outbursts of Coal (Rock) and Gas. Stresses and Strains, Preprint No. 155, (Institute of Mechanical Problems of the RAS, Moscow, 1980) (in Russian).

11. V.V. Khodot, Sudden Outbursts of Coal and Gas (Gosgortekhizdat, Moscow, 1961) (in Russian).

Received 27.10.11

НЕРІВНОВАЖНА ТЕРМОДИНАМІКА I ВИКИДОНЕБЕЗПЕЧНІСТЬ ВУГІЛЬНОГО ПЛАСТА

А.Д. Алєксєєв, Е.П. Фельдман

Р ез ю м е

Запропонована робота подає теоретичну побудову нерівноважної термодинаміки газовмісних вугільних пластів та кількісну оцінку їх викидонебезпечності. 